\title{
Dark Anaerobic Hydrogen Production in the Mutants of Synechocystis sp. Strain PCC6803-GT Defective in Lactate Dehydrogenase Activity and/or Alcohol Dehydrogenase Activity, Incubated in Buffer Solutions With or Without Glucose
}

\author{
Adipa Chongsuksantikul ${ }^{1}$ Kazuhiro Asami $^{1}$, Shiro Yoshikawa ${ }^{1} \&$ Kazuhisa Ohtaguchi $^{1}$ \\ ${ }^{1}$ Tokyo Institute of Technology, Japan \\ Correspondence: Adipa Chongsuksantikul, Tokyo Institute of Technology, Japan. E-mail: adipa.c.aa@m.titech.ac.jp
}

Received: September 5, 2014 Accepted: September 22, $2014 \quad$ Online Published: October 20, 2014

doi:10.5539/ijb.v7n1p33 URL: http://dx.doi.org/10.5539/ijb.v7n1p33

\begin{abstract}
To redirect $\mathrm{NAD}(\mathrm{P}) \mathrm{H}$ consumed by dehydrogenases to NiFe-hydrogenase, the genes encoding for lactate dehydrogenase $(d d h)$ and alcohol dehydrogenase $(a d h)$ were disrupted in a glucose tolerant mutant of unicellular cyanobacterium Synechocystis sp. strain PCC6803 (GT strain). The cells of GT strain, ddh deficient ( $\Delta$ ddh) mutant and both adh and ddh deficient $(\Delta \mathrm{adh} \Delta \mathrm{ddh})$ mutant were harvested at the late-logarithmic growth phase of photoautotrophic culture in antibiotic-free BG-11 medium. Dark anaerobic hydrogen production in GT strain, $\Delta$ ddh mutant and $\Delta \mathrm{adh} \Delta \mathrm{ddh}$ mutant in nitrate-free HEPES buffer solution without or with glucose has been studied by following the time courses of the number of moles of hydrogen, endogenous and exogenous glucose, lactate, acetate and ethanol per culture volume and the dry cell weight concentration. Dark incubation of cells of $\Delta$ ddh mutant and $\Delta \mathrm{adh} \Delta \mathrm{ddh}$ mutant in HEPES buffer solution without glucose resulted 1.16-fold and 1.15-fold increases in the initial hydrogen production rates over GT strain, respectively, while 1.1-fold and 0.85-fold increases in the number of moles of hydrogen per culture volume at $96 \mathrm{~h}$ over GT strain, respectively. When hydrogen production experiments were performed in the glucose-added HEPES buffer solution, dark incubation of cells of $\Delta$ ddh mutant and $\Delta \mathrm{adh} \Delta \mathrm{ddh}$ mutant resulted 1.4-fold and 1.6-fold increases in the initial hydrogen production rates over GT strain without glucose run, respectively, while 1.5-fold and 1.3-fold increases in the number of moles of hydrogen per culture volume at $96 \mathrm{~h}$ over GT strain without glucose run, respectively.
\end{abstract}

Keywords: alcohol dehydrogenase, cyanobacteria, dark anaerobic, glucose, hydrogen production, lactate dehydrogenase, mutant, Synechocystis

\section{Introduction}

The glucose tolerant mutant of unicellular cyanobacterium Synechocystis sp. strain PCC6803 (GT strain) is transformable and represents both photoautotrophic growth on carbon dioxide and heterotrophic growth on glucose (Rippka et al., 1979; Kufryk et al., 2002). During phototrophic growth, carbon dioxide is incorporated into ribulose bisphosphate $(\mathrm{RuBP})$ in the Calvin cycle to form 3-P-glycerate that is further converted to glucose in glycogen for storage utilizing the ATP and NADPH produced by the light-dependent reactions. During heterotrophic growth, exogenous glucose is transported into the cell through glucose-fructose transporter and phosphorylated to form glucose 6-phosphate that is also converted to glycogen. Generations of ATP and $\mathrm{NAD}(\mathrm{P}) \mathrm{H}$ by glycogen decomposition by either aerobic respiration or anaerobic glycolysis have been applied for molecular hydrogen production on bidirectional NiFe-hydrogenase (Antal and Lindblad 2005; Cournac et al., 2004). If hydrogen production in the dark is associated with breakdown of glycogen to pyruvate via oxidative pentose phosphate (OPP) pathway, glucose 6-phosphate dehydrogenase, 6-phosphogluconate dehydrogenase and glyceraldehyde-3-phosphate dehydrogenase contribute a supply of $\mathrm{NAD}(\mathrm{P}) \mathrm{H}$ for hydrogenase. Different from those enzymes, under the fermentative condition, D-lactate dehydrogenase (ddh) assimilates NADH by converting pyruvate to D-lactate (hereafter lactate) and alcohol dehydrogenase (adh) assimilates NADPH by concerting acetaldehyde to ethanol. The ddh for lactate production and the adh for ethanol production compete NAD $(\mathrm{P}) \mathrm{H}$ with NiFe-hydrogenase for hydrogen production. If disruption of the genes coding for a NAD(P)H-dependent enzyme results a variation in redox balance of GT strain, such mutation appears to present a good outlook for increasing hydrogen production. 
A previous work on the growth of mutant of Thermoanaerobacterium strain defective of L-lactate dehydrogenase genes (ldh) on $100 \mu \mathrm{mol} \mathrm{mL} \mathrm{m}^{-1}$ xylose shows the 2- and 2.5 -folds increases in hydrogen production yield and hydrogen production rate, respectively ( $\mathrm{Li}$ et al.,, 2010). When grown on glucose, hydrogen fermentation of 1dh-deleted Escherichia coli was superior to that of wild type strain (Maeda et al., 2007). Dark incubation of a cyanobacterium Synechococcus sp. strain PCC7002 and that lacking the enzyme for the NADH-dependent reduction of pyruvate to D-lactate $(\Delta d d h \mathrm{~A})$ results 11 and 55 mole hydrogen per $10^{17}$ cells $(=0.0384$ and 0.215 $\mu \mathrm{mol} \mathrm{mL}{ }^{-1}$ ), respectively (McNeely et al., 2010). In our previous publication, we reported the successful variation in the hydrogen production of GT strain by disrupting the genes coding for $d d h$ with aiming at elevating the level in the amount of intracellular NADH for bidirectional hydrogenase (Yamamoto et al., 2012). The keyword search on the genome database of Synechocystis sp. strain PCC6803 utilizing CyanoBase (http://genome.kazusa.or.jp/cyanobase/) hits 41 genes for NADH and 9 genes for NADPH. Among them this study concerns $a d h$ genes in slr0942 that is a manager of carbonyls received from glycolysis system (Shimakawa et al., 2013). Synechocystis sp. strain PCC6803 can naturally convert pyruvate to acetate that is further reduced via adh to a small amount of ethanol in dark anaerobic condition. There is a report that shows a construction of a mutant of Synechocystis sp. strain PCC6803 with genes coding for $a d h$ and pyruvate decarboxylase ( $p d c)$ of Zymomonas mobilis and a production of $120 \mu \mathrm{mol} \mathrm{mL}^{-1}$ ethanol phototrophically from carbon dioxide (Gao et al., 2012; Dehring et al., 2012). Although aldehyde is toxic to Synechocystis sp. strain PCC6803, cells are protected by converting it to ethanol.

In order to gain more insight into the effect of elimination of single or multiple $\mathrm{NAD}(\mathrm{P}) \mathrm{H}$ consumption reactions that compete $\mathrm{NAD}(\mathrm{P}) \mathrm{H}$ with NiFe-hydrogenase in dark anaerobic nitrate-free condition, in the present work, we disrupt not only genes coding for D-lactate dehydrogenase $(d d h)$ but also genes coding for alcohol dehydrogenase $(a d h)$ in a glucose tolerant mutant of Synechocystis sp. strain PCC6803 and compare the hydrogen production of GT strain, ddh deficient ( $\Delta \mathrm{ddh}$ ) mutant with both $a d h$ and $d d h$ deficient ( $\Delta \mathrm{adh} \Delta \mathrm{ddh}$ ) mutant in the HEPES buffer solution without and with glucose. The $a d h$ gene and $d d h$ gene are selected and targeted to be deleted in order to modify the size of protein to be expressed and to alter the homeostasis network to generate $\mathrm{NAD}(\mathrm{P}) \mathrm{H}$ for NiFe-hydrogenase pathway.

\section{Material and Method}

\subsection{Mutant Constructions}

The competent cells of Escherichia coli X1-Blue were used for transformation purposes. E.coli cells were cultured at $37{ }^{\circ} \mathrm{C}$ in $2 \mathrm{~mL}$ LB medium in $24.5 \mathrm{~mL}$ clear Pyrex glass test tube (TE-32, AGC TECHNO GLASS Co. Ltd.) which were shaken at $220 \mathrm{rpm}$ in a shaking incubator. The wild-type host cyanobacterium used in this study was a glucose tolerant mutant of Synechocystis sp. strain PCC6803 (GT strain). Sequences of cyanobacterium Synechocystis sp. strain PCC6803 were retrieved from Kyoto Encyclopedia of Genes and Genomes (KEGG). Primers were 5'GCCTATGATCGTCAATTTTTCC3' and 5'TTCAGCAATATTTGCCAGTGTC3' for $d d h$ (slr1556) and 5'CAAAAGCATTGTCCGCCTCACC3' and 5'GCTTCCGCTTGGGAGTGCC3' for adh (slr0942).

The $\Delta$ ddh mutant lacking $d d h(\operatorname{slr} 1556:: \mathrm{Km})$ was constructed by ligating PCR-amplified $d d h$ fragment into a plasmid pUC19 at SmaI. The product was then digested with BglII before the ligation of kanamycin resistance gene cassette from pUC4K. Sizes of $l d h$ gene and $K m^{\mathrm{r}}$ gene were $1.002 \mathrm{~kb}$ and $0.543 \mathrm{~kb}$, respectively, hence the disruption of $l d h$ gene results in the $0.459 \mathrm{~kb}$ decrease in the size of DNA. The $\Delta \mathrm{adh} \Delta \mathrm{ddh}$ mutant lacking both $a d h$ and $d d h$ (slr1556::Km,slr0942::Sm/Sp) was constructed by ligating PCR-amplified $a d h$ fragment into a plasmid pMD19 at $E c o R V$ site. The streptomycin/spectinomycin resistance gene cassette $\left(S m^{\mathrm{r}} / S p^{\mathrm{r}}\right)$ from plasmid $\mathrm{pHP} 45-\Omega$ was inserted into the $E c o R V$ restriction site on $a d h$ gene fragment. Sizes of $a d h$ gene and $S m^{\mathrm{r}} / S p^{\mathrm{r}}$ gene were 0.981 $\mathrm{kb}$ and $2.0 \mathrm{~kb}$ (Prentki and Krisch, 1984), hence the disruption of $l d h$ gene and $a d h$ gene resulted in the $0.56 \mathrm{~kb}$ increase in the size of DNA. Experimental technique to decrease or increase DNA size results in decrease or increase in the amount of $\mathrm{NAD}(\mathrm{P}) \mathrm{H}$ that is required for protein synthesis.

Transformant colonies of $\Delta \mathrm{ddh}$ mutant and $\Delta \mathrm{adh} \Delta \mathrm{ddh}$ mutant were selected from the plates containing kanamycin and both kanamycin and streptomycin, respectively, and continuously re-streaked to new plates. Antibiotic resistant cells were grown on BG-11 medium plates at increasing antibiotic concentrations and finally transferred into liquid medium (BG-11). The cells of $\Delta$ ddh mutant and $\Delta \mathrm{adh} \Delta \mathrm{ddh}$ mutant were grown on BG-11 medium supplemented with $60 \mu \mathrm{mol} \mathrm{mL}{ }^{-1}$ kanamycin, and that with both $60 \mu \mathrm{mol} \mathrm{mL} \mathrm{L}^{-1}$ kanamycin and $2.5 \mu \mathrm{mol} \mathrm{mL}$ streptomycin, respectively. Mutant cells were harvested and washed to remove antibiotics before the inoculation into to the photoautotrophic main cultures in the light. 


\subsection{Photoautotrophic Growth for Inoculum Preparation}

Cells of GT strain, $\Delta \mathrm{ddh}$ mutant and $\Delta \mathrm{adh} \Delta \mathrm{ddh}$ mutant of Synechocystis sp. strain PCC6803 were grown photoautotrophically in $60 \mathrm{~mL}$ antibiotic-free BG-11 medium (initial $\mathrm{pH} 7.8$ ) that was aerated by $6 \%$ carbon dioxide in the air in clear Pyrex glass test tube (TE-32, AGC TECHNO GLASS Co. Ltd.) at $34{ }^{\circ} \mathrm{C}$ in water bath, surface of which was exposed to fluorescent lamps with a photosynthetic photon flux density (PPFD) of 100 $\mu$ mol-photons $\mathrm{m}^{-2} \mathrm{~s}^{-1}$. Growth was monitored by measuring $\mathrm{OD}_{730}$ of cell suspension. One unit of $\mathrm{OD}_{730}$ represents the dry cell weight concentration $(X)$ of $0.369 \mathrm{mg} \mathrm{mL}^{-1}$. In preliminary experiments it was observed that cells were in late-logarithmic growth phase when $\mathrm{OD}_{730}$ of cell suspensions was 7. Cultures of GT strain, $\Delta$ ddh mutant and $\Delta \mathrm{adh} \Delta \mathrm{ddh}$ reached these OD730 cultivations, respectively. Cultures of $\mathrm{OD}_{730}$ at 7 were centrifuged at $3000 \mathrm{rpm}$ for 10 min at $25^{\circ} \mathrm{C}$.

\subsection{Dark Anaerobic Incubation for Hydrogen Production}

The cell pellets were washed, re-suspended and incubated in $10 \mathrm{~mL}$ of either 50 mmol L-1 HEPES (4-(2-hydroxyethyl)-1-piperazineethanesulfonic acid)) buffer (pH 7.8) or $50 \mathrm{mmol} \mathrm{L}^{-1}$ HEPES buffer ( $\mathrm{pH} 7.8$ ) with $5 \mathrm{mmol} \mathrm{L}^{-1}$ glucose in $32 \mathrm{~mL}$ glass test tube with butyl rubber cap. HEPES was selected for $\mathrm{pH}$ control preventing a drastic drop in $\mathrm{pH}$ during fermentation. The initial dry cell mass weight concentration was set at $2 \mathrm{mg}$ $\mathrm{mL}^{-1}$ and cell suspension was purged with nitrogen gas for a few minutes to remove oxygen gas. Incubation of cell suspension in test tube was carried out under dark anaerobic conditions, shaking at $145 \mathrm{rpm}$ in a reciprocating shaker. The reciprocating distance was $40 \mathrm{~mm}$ and the horizontal angle was about $30^{\circ} \mathrm{C}$. All experiments were carried out in duplicate.

The number of moles of hydrogen per culture volume $\left(y_{\mathrm{H} 2}\right)$ was determined by analyzing the composition of gas phase in $32 \mathrm{~mL}$ test tube utilizing gas chromatograph and thermal conductivity detector (GC-320, GL science Inc.; column, Molecular sieve $13 \mathrm{X}$; carrier gas, nitrogen gas; column temperature, $37^{\circ} \mathrm{C}$; injector temperature, $45^{\circ} \mathrm{C}$; detector temperature $80{ }^{\circ} \mathrm{C}$ ).

The amount of cellular glycogen was estimated in terms of the number of moles of glucose equivalent. The number of moles of endogenous glucose per dry cell weight $\left(m_{\mathrm{G}}\right)$ was determined as follows: the amount of dry cell weight per culture volume was determined according to previous report (Yamamoto et al., 2012); cell pellets were collected by centrifugation at $25{ }^{\circ} \mathrm{C}, 3000 \mathrm{rpm}$ for $10 \mathrm{~min}$ then washed 3 times by deionized water to eliminate extracellular carbon sources; intracellular glycogen was extracted and decomposed to glucose in $50 \mu \mathrm{L}$ of $6 \mathrm{~N} \mathrm{HCl}$ at $80^{\circ} \mathrm{C}$ for $30 \mathrm{~min}$; glucose amount was determined by using Glucose CII Test Wako (Wako Pure Chemical Ind., Ltd.). The number of moles of endogenous glucose per culture volume $\left(m_{\mathrm{G}} X\right)$ was calculated from $m_{\mathrm{G}}$ and $X$. For experiments with exogenous glucose, the number of moles of glucose per culture volume $\left(c_{\mathrm{s}}\right)$ was analyzed by HPLC.

Exogenous glucose dissolved in supernatant was analyzed by HPLC (Shimadzu LC-10AD and RID-6A) with a $6.0 \times 150 \mathrm{~mm}$ column SZ5532 (Showa Denko Co.). Mobile phase was $70 \%$ acetonitrile with water. Mobile phase flow rate was $0.7 \mathrm{~mL} / \mathrm{min}$. Column temperature was set at $50^{\circ} \mathrm{C}$.

Extracellular concentrations of lactate $\left(c_{\mathrm{L}}\right)$ and acetate $\left(c_{\mathrm{A}}\right)$ in a $500 \mu \mathrm{L}$ portion of supernatants were analyzed by HPLC (JASCO PU-2080 Plus and UV-2075 Plus). Mobile phase was $18 \mathrm{mmol} \mathrm{L}^{-1} \mathrm{KH}_{2} \mathrm{PO}_{4}$, pH of which was adjusted at 2.3 with $\mathrm{H}_{3} \mathrm{PO}_{4}$. Flow rate of mobile phase was $0.7 \mathrm{~mL} \mathrm{~min}^{-1}$. Column temperature was $30^{\circ} \mathrm{C}$. A $10 \mu \mathrm{L}$ of supernatant sample was injected by using $10 \mu \mathrm{L}$ syringes. The wave length of $210 \mathrm{~nm}$ was used for detection of metabolites. Ethanol $\left(c_{\mathrm{E}}\right)$ in supernatant was analyzed by by HPLC (Shimadzu LC-10AD and RID-6A) with a 6.0 $\times 150 \mathrm{~mm}$ column SZ5532 (Showa Denko Co.). Column temperature was set at $50^{\circ} \mathrm{C}$. Mobile phase was $5 \mathrm{mmol}$ $\mathrm{L}^{-1}$ sulfuric acid.

\section{Results}

\subsection{Construction of $\Delta d d h$ Mutant and $\Delta a d h \Delta d d h$ Mutant}

Figure 1 represents the partial restriction maps of (a) the $d d h$ in slr1556 cloned into the SmaI site of pUC19, the slr1556:: $\mathrm{Km}^{\mathrm{r}}$ containing the kanamycin resistance gene inserted into the $B g l I I$ site in the $d d h$ in slr1556 and (b) the adh in slr0942 cloned into the EcoRV site of $\mathrm{pMD} 19$ and the slr0942:: $\mathrm{Sm}^{\mathrm{r}} / \mathrm{Sp}^{\mathrm{r}}$ containing the streptomycin/spectinomycin registance gene inserted into the $E c o R \mathrm{~V}$ restriction site on adh gene. Wild-type

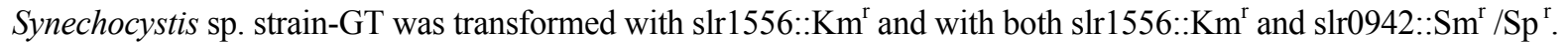


(a)

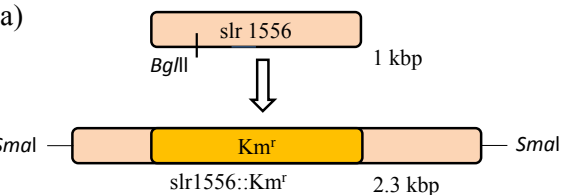

(b)

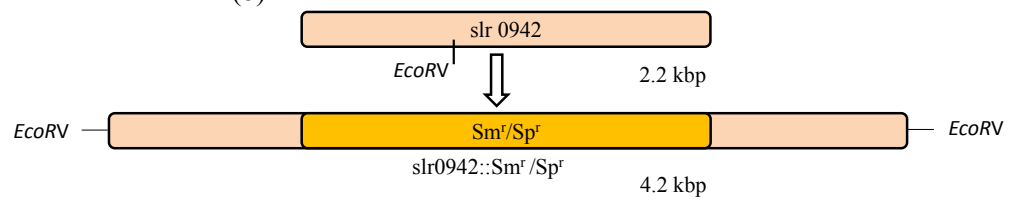

Figure 1. Construction of vectors, (a) $\operatorname{slr} 1556:: \mathrm{Km}^{\mathrm{r}}$ and (b) slr0942:: $\mathrm{Sm}^{\mathrm{r}} / \mathrm{Sp}^{\mathrm{r}}$

Photographs in Figure 2 show results of agarose-gel electrophoretic analyses of PCR products for evaluating the achievement of deletion of (a) $d d h$ genes and (b) both $a d h$ and $d d h$ genes. Photograph (a) shows Lane 1: size marker DNA, Lane 2: PCR product for ddh primers and $\mathrm{pUC19}$-slr1556: $\mathrm{Km}^{\mathrm{r}}$, Lane 3: PCR product for ddh primers and genomic DNA from GT strain, and Lane 4:PCR product with ddh primers and genomic DNA from $\Delta$ ddh mutant. Photograph (b) shows Lane 1: size marker DNA, Lane 2: PCR product for ddh primers and pUC19-slr1556: $\mathrm{Km}^{\mathrm{r}}$, Lane 3: PCR product for adh primers and pMD19-slr0942:: $\mathrm{Sp}^{\mathrm{r}} \mathrm{Sm}^{\mathrm{r}}$, Lane 4: PCR product for ddh primers and genomic DNA from GT strain, Lane 5: PCR product for adh primers and genomic DNA from GT strain, Lane 6: PCR product for ddh primers and DNA from $\Delta \mathrm{adh} \Delta \mathrm{ddh}$ mutant and Lane 7: PCR product for adh primers and genomic DNA from $\Delta \mathrm{adh} \Delta \mathrm{ddh}$ mutant. The successful segregation of $\Delta \mathrm{ddh}$ is confirmed, ((a) Lane 4 or (b) Lane 6) is the same size as that for primers and DNA fragment from pUC19-slr1556:Km ${ }^{\mathrm{r}}$ ((a) or (b) Lane 2). Double mutation is also confirmed by the result showing that the size of PCR product for primers and genomic DNA from $\Delta \mathrm{adh} \Delta \mathrm{ddh}$ mutant ((b) Lane 7) is the same size as that for primers and DNA fragment from pMD19-slr0942::: $\mathrm{Sp}^{\mathrm{r}} / \mathrm{Sm}^{\mathrm{r}}$ ( (b) Lane 3).

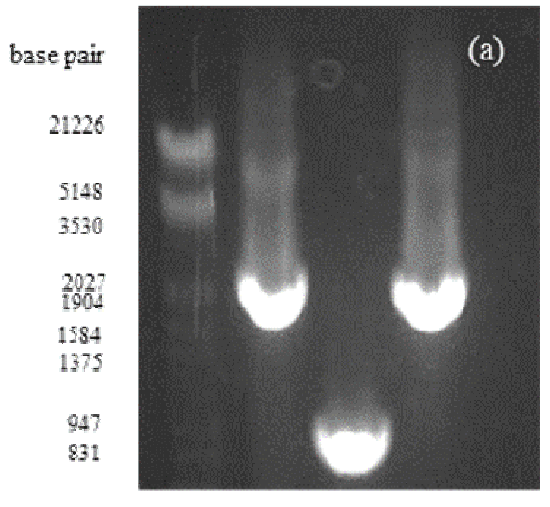

Lane

$\begin{array}{llll}1 & 2 & 3 & 4\end{array}$

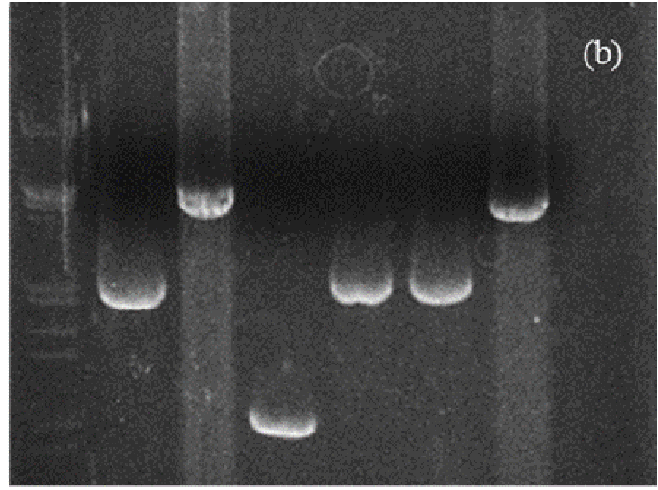

$\begin{array}{lllllll}1 & 2 & 3 & 4 & 5 & 6 & 7\end{array}$

Figure 2 Agarose-gel electrophoretic analyses of PCR products for evaluating the achievement of (a) $\Delta$ ddh mutation and (b) $\Delta \mathrm{adh} \Delta \mathrm{ddh}$ mutation

\subsection{Characteristics of Photoautotrophic Growth}

Precultures for photoautotrophic growth of GT strain, $\Delta$ ddh mutant and $\Delta \mathrm{adh} \Delta \mathrm{ddh}$ mutant were performed on BG-11 medium, BG-11 medium containing $60 \mu \mathrm{mol} \mathrm{mL}{ }^{-1}$ kanamycin and BG-11 medium containing $60 \mu \mathrm{mol}$ $\mathrm{mL}^{-1}$ kanamycin and $2.5 \mu \mathrm{mol} \mathrm{mL} \mathrm{m}^{-1}$ streptomycin, respectively. At $96 \mathrm{~h}$ of precultures, cells were harvested, washed and then inoculated into main cultures in which cells were grown photoautotrophically in antibiotic-free BG-11 medium. Growth of cells on BG-11 was monitored by optical density at $730 \mathrm{~nm}$ wavelength. Growth curves for GT strain, $\Delta$ ddh mutant and $\Delta \mathrm{adh} \Delta \mathrm{ddh}$ mutant show that cells of GT strain and $\Delta$ ddh mutant were in logarithmic growth phase from $0 \mathrm{~h}$ to $24 \mathrm{~h}$ and from $0 \mathrm{~h}$ to $40 \mathrm{~h}$, respectively, while $\Delta \mathrm{adh} \Delta \mathrm{ddh}$ mutant was in lag phase from $0 \mathrm{~h}$ to $24 \mathrm{~h}$ and in logarithmic growth phase from $24 \mathrm{~h}$ to $48 \mathrm{~h}$ (Figure 3). 


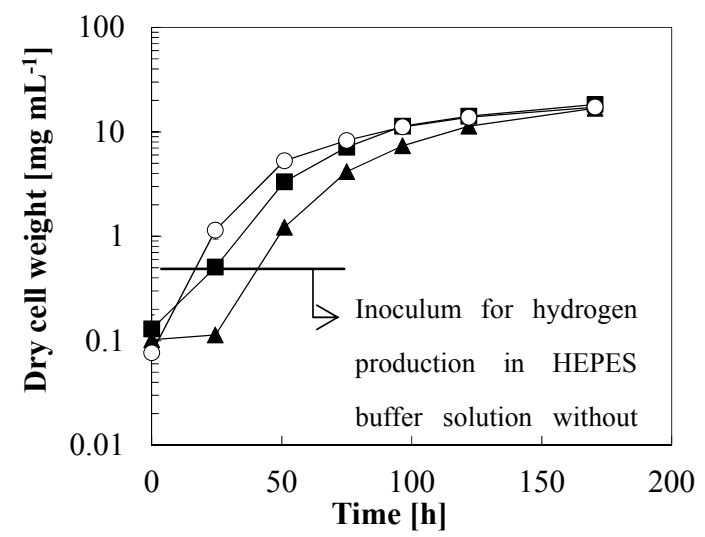

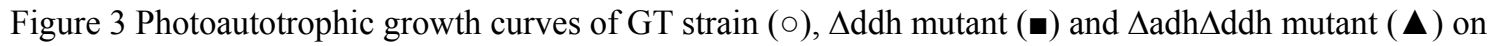
antibiotic-free BG-11 medium. Pre-culture cells of GT strain, $\Delta$ ddh mutant and $\Delta \mathrm{adh} \Delta \mathrm{ddh}$ mutant were grown on BG-11 medium, BG-11 medium with $60 \mathrm{mg} \mathrm{mL}^{-1}$ kanamycin and BG-11 medium with both $60 \mathrm{mg} \mathrm{mL}^{-1}$ kanamycin and $2.5 \mathrm{mg} \mathrm{mL}^{-1}$ streptomycin, respectively. Cells were washed by sterilized distilled-water to remove antibiotics prior to main culture. The horizontal line pointing the level of $X$ at $2.58 \mathrm{mg} \mathrm{mL}^{-1}$ represents the culture-harvest ion time when $\mathrm{OD}_{730}$ of cell suspensions is 7

The lag time for the growth of $\Delta \mathrm{adh} \Delta \mathrm{ddh}$ mutant appears to represent a period for adaptation of the mutant from antibiotic containing preculture medium to antibiotic-free main culture medium. After one week cultivation, dry cell weight concentrations of $\Delta \mathrm{ddh}$ mutant and $\Delta$ adhddh mutant reached the same level as GT strain.

Carbon dioxide is a single carbon source for cell growth, hence the slope of growth curve represents the activity of carbon dioxide fixation. Total amount of carbon dioxide incorporated into dry cell weight during $168 \mathrm{~h}$ cultivation is found not to be affected by deletion of $a d h$ or $d d h$ genes. The inoculum cells of GT strain, $\Delta$ ddh mutant and $\Delta \mathrm{adh} \Delta \mathrm{ddh}$ mutant for dark anaerobic hydrogen production was harvested at 36,45 , and $60 \mathrm{~h}$, respectively.

The $\mathrm{OD}_{730}$ at the cell-harvest ion time was fixed, hence inoculum cells for hydrogen production experiment were confirmed to be exposed to same PPFD from incident light to transmitted light. The slope of growth curves $(\mathrm{d} \ln X / \mathrm{d} t)$ of GT strain, $\Delta \mathrm{ddh}$ mutant and $\Delta \mathrm{adh} \Delta \mathrm{ddh}$ mutant of the $X$ at $2.58 \mathrm{mg} \mathrm{mL}^{-1}$ are $0.0187,0.0318$ and $0.0238 \mathrm{~h}^{-1}$ respectively. The cell formula of Synechocystis sp. strain PCC6803 shown in a reference is $\mathrm{CH}_{1.62}$ $\mathrm{N}_{0.22} \mathrm{O}_{0.40} \mathrm{P}_{0.11}$ (Yu et al., 2013), hence the rates of carbon dioxide assimilation by inocula of GT strain, $\Delta$ ddh mutant and $\Delta \mathrm{adh} \Delta \mathrm{ddh}$ mutant are calculated as $2.09,3.55$ and $2.66 \mu \mathrm{mol} \mathrm{mL}^{-1} \mathrm{~h}^{-1}$, respectively and the rates of NADPH consumption at the Calvin cycle are calculated as $4.18,7.10$ and $5.32 \mu \mathrm{mol} \mathrm{mL}^{-1} \mathrm{~h}^{-1}$, respectively.

\subsection{Characteristics of Dark Anaerobic Nitrate-Free Hydrogen Production in the Absence of Glucose}

In the first series, photoautotrophic cells of GT strain, $\Delta$ ddh mutant or $\Delta \mathrm{adh} \Delta \mathrm{ddh}$ mutant in late-logarithmic growth phase was incubated at $2.58 \mathrm{mg} \mathrm{mL}^{-1}$ dry cell weight concentration in dark anaerobic nitrate-free HEPES buffer solution without glucose. Similar to photoautotrophic culture, the solution for hydrogen production was free from antibiotics. Figure 4 shows the time courses of the number of moles per culture volume of (a) hydrogen $\left(y_{\mathrm{H} 2}\right)$ and (b) endogenous glucose in glycogen $\left(m_{\mathrm{G}} X\right)$, and the concentrations of (c) dry cell weight $(X)$, (d) lactate $\left(c_{\mathrm{L}}\right)$ and (e) acetate $\left(c_{\mathrm{A}}\right)$. Ethanol concentration of run with GT strain, $\Delta \mathrm{ddh}$ mutant or $\Delta \mathrm{adh} \Delta \mathrm{ddh}$ mutant in the absence of glucose was not in detectable level, hence time course data for it were not plotted in Figure 4.

Hydrogen production characteristics in the absence of glucose: If subscript 1 shows the state at $96 \mathrm{~h}$, the $y_{\mathrm{H} 2,1}$ values of runs with GT strain, $\Delta$ ddh mutant and $\Delta \mathrm{adh} \Delta \mathrm{ddh}$ mutant are $1.8,2.0$ and $1.5 \mu \mathrm{mol} \mathrm{mL}^{-1}$, respectively (Figure4(a)). The $y_{\mathrm{H} 2,1}$ of $\Delta \mathrm{ddh}$ mutant is 1.11 times that of GT strain. The $y_{\mathrm{H} 2,1}$ of $\Delta \mathrm{ddh}$ mutant shown in our previous report (Yamamoto et al., 2012) was 1.5 times that of GT strain. Previous work and present work utilized the inocula from logarithmic growth phase and late-logarithmic growth phase, respectively. Growth phase is suggested to be of utmost important factor for hydrogen production. The elimination of adh activity resulted to decrease $y_{\mathrm{H} 2,1}$ that was 0.83 times that of GT strain, The highest $y_{\mathrm{H} 2,1}$ was observed in run with $\Delta \mathrm{ddh}$ mutant, second highest is in run with GT strain and the lowest is in run with $\Delta \mathrm{adh} \Delta \mathrm{ddh}$ mutant. This descending order is same as the ascending order of the modified DNA size shown in Table 1. The DNA size of $\Delta \mathrm{adh} \Delta \mathrm{ddh}$ mutant is $0.56 \mathrm{~kb}$ larger than that of GT strain, hence expression of increased DNA size appears to increase the NAD(P)H consumption for protein and amino acid synthesis and reduce the hydrogen production. On the other hand, the DNA size of $\Delta \mathrm{ddh}$ mutant is $0.459 \mathrm{~kb}$ smaller than that of GT strain, hence expression of decreased DNA size 
appears to decrease the $\mathrm{NAD}(\mathrm{P}) \mathrm{H}$ consumption for protein and amino acid synthesis and increase the hydrogen production.

The time courses of $y_{\mathrm{H} 2}$ show that the production of hydrogen by those three strains was highest right after inoculation and deactivated with time. The $y_{\mathrm{H} 2}$ versus time data fit the equation:

$$
\left.\left.y_{H 2}=y_{H 2, f}\{1-\exp (-k t))\right\}=\frac{r_{H 2,0}}{k}\{1-\exp (-k t))\right\}
$$

in which $y_{\mathrm{H} 2, \mathrm{f}}$ is the attainable level of $y_{\mathrm{H} 2}, k$ is the deactivation constant for hydrogen production and $r_{\mathrm{H} 2,0}$ is the initial hydrogen production rate. The curves in Figure 4(a) for GT strain, $\Delta$ ddh mutant and $\Delta$ adh $\Delta$ ddh mutant are calculated with the values of $y_{\mathrm{H} 2, \mathrm{f}}$ and $k$ in Table 1 . The calculated $y_{\mathrm{H} 2}$ agrees well with the observed $y_{\mathrm{H} 2}$. The descending order of $y_{\mathrm{H} 2, \mathrm{f}}$ in Table 1 is same as the descending order of the $y_{\mathrm{H} 2,1}$.

The $r_{\mathrm{H} 2,0}$ of Table 1 is highest for run with $\Delta$ ddh mutant, comparable second highest for run with $\Delta \mathrm{adh} \Delta \mathrm{ddh}$ mutant and lowest for run with GT strain. The descending order of $r_{\mathrm{H} 2,0}$ is similar to that of the consumption rate of $\mathrm{NAD}(\mathrm{P}) \mathrm{H}$ in the Calvin cycle just before inoculation (Table 1). Shift of cellular environment from illuminated aerobic nitrate-containing BG-11 medium to dark anaerobic nitrate-free HEPES buffer solution appears to redirect the accumulated $\mathrm{NAD}(\mathrm{P}) \mathrm{H}$ molecules in the Calvin cycle to NiFe-hydrogenase.

Table 1. Kinetic parameters of dark anaerobic hydrogen production in GT strain, $\Delta$ ddh mutant and $\Delta \mathrm{adh} \Delta \mathrm{ddh}$ mutant in HEPES buffer solution without or with glucose

\begin{tabular}{|c|c|c|c|c|c|c|}
\hline Strain & $\begin{array}{c}\text { Increase in } \\
\text { DNA size } \\
{[\mathrm{kb}]}\end{array}$ & $\begin{array}{l}\mathrm{NAD}(\mathrm{P}) \mathrm{H} \text { production rate in } \\
\text { the Calvin cycle before } \\
\text { inoculation }\left[\mu \mathrm{mol} \mathrm{mL}^{-1} \mathrm{~h}^{-1}\right]\end{array}$ & $\begin{array}{l}\text { HEPES } \\
\text { buffer } \\
\text { additives }\end{array}$ & $\begin{array}{c}r_{\mathrm{H} 2,0} \\
{\left[\mu \mathrm{mol} \cdot \mathrm{mL}^{-1} \cdot \mathrm{h}^{-1}\right]}\end{array}$ & $\begin{array}{c}k \\
{\left[\mathrm{~h}^{-1}\right]}\end{array}$ & $\begin{array}{c}y_{\mathrm{H} 2, \mathrm{f}} \\
{\left[\mu \mathrm{mol} \cdot \mathrm{mL}^{-1}\right]}\end{array}$ \\
\hline \multirow{2}{*}{ GT strain } & \multirow{2}{*}{0} & \multirow{2}{*}{4.18} & w/o glucose & 0.0309 & 0.0167 & 2.28 \\
\hline & & & with glucose & 0.0901 & 0.0184 & 5.61 \\
\hline \multirow{2}{*}{$\begin{array}{l}\Delta \mathrm{ddh} \\
\text { mutant }\end{array}$} & \multirow{2}{*}{-0.495} & \multirow{2}{*}{7.10} & w/o glucose & 0.0359 & 0.0213 & 2.31 \\
\hline & & & with glucose & 0.0430 & 0.0145 & 3.48 \\
\hline \multirow{2}{*}{$\begin{array}{l}\Delta \mathrm{adh} \Delta \mathrm{ddh} \\
\text { mutant }\end{array}$} & \multirow{2}{*}{0.56} & \multirow{2}{*}{5.32} & w/o glucose & 0.0355 & 0.0365 & 1.48 \\
\hline & & & with glucose & 0.0502 & 0.0299 & 2.45 \\
\hline
\end{tabular}

The elimination of ddh activity or both adh and ddh activities results in 1.16-fold increase or 1.15-fold increase in the $r_{\mathrm{H} 2,0}$. Considering that the NiFe-hydrogenase converts $1 \mu \mathrm{mol} \mathrm{NAD}(\mathrm{P}) \mathrm{H}$ to form $1 \mu$ mol hydrogen, this result shows that the amount of NADH consumed by lactate dehydrogenase of GT strain is about $16 \%$ of the total amount of NADH and NADPH consumed by NiFe-hydrogenase of GT strain. The initial lactate production rate was $0.000833 \mu \mathrm{mol} \mathrm{mL}{ }^{-1} \mathrm{~h}^{-1}$ in GT strain and almost $0 \mu \mathrm{mol} \mathrm{mL}^{-1} \mathrm{~h}^{-1}$ in $\Delta \mathrm{ddh}$ and $\Delta \mathrm{adh} \Delta \mathrm{ddh}$ mutants (Figure $4 \mathrm{~d}$ ). Stoichiometry of D-lactate dehydrogenase and NiFe-hydrohenase suggests that the elimination of above lactate production rate potentially increases hydrogen production rate from $0.0309 \mu \mathrm{mol} \mathrm{mL}^{-1} \mathrm{~h}^{-1}$ to $0.0359 \mu \mathrm{mol} \mathrm{mL}^{-1} \mathrm{~h}^{-1}$. The observed increase is 6 times more than the estimated increase by ddh elimination. Redirection of carbon metabolism at pyruvate from lactate production to acetyl-CoA production is found to amplify $\mathrm{NAD}(\mathrm{P}) \mathrm{H}$ production.

A 1.28 -fold increase in $\Delta$ ddh mutant and a 2.19 -fold increase in $\Delta \mathrm{adh} \Delta \mathrm{ddh}$ mutant over GT strain in the deactivation constant $k$ are seen in the results (Table 1). The presence of dehydrogenases in GT strain appears to be important to stabilize the dynamical redox adaptation of cells against continuous consumption of $\mathrm{NAD}(\mathrm{P}) \mathrm{H}$ on NiFe-hydrogenase.

The attainable level of $y_{\mathrm{H} 2}$ by $\Delta \mathrm{ddh}$ mutant is comparable with that of GT strain, while that by $\Delta \mathrm{adh} \Delta \mathrm{ddh}$ mutant is 0.65 times that of GT strain. For hydrogen production in the absence of exogenous glucose, stabilization is of first importance for high production of hydrogen by $\Delta \mathrm{adh} \Delta \mathrm{ddh}$ mutant. Our result of $\Delta \mathrm{ddh}$ mutant in Synechocystis sp. strain PCC6803 differs from that of $\Delta$ ddhA mutant in Synechococcus sp. strain PCC7002 (McNeely et al., 2010) that shows 5-fold increase in hydrogen production from wild type strain, however the attainable level of hydrogen $\left(y_{\mathrm{H} 2, \mathrm{f}}\right)$ in this experiment is 10 times that shown by their experiment.

Endogenous glucose consumption characteristics in the absence of glucose: The $m_{\mathrm{G}} X$ of runs with three strains decreased or kept constant with time (Figure4(b)). Although hydrogen productions in three strains were highest at 
initial, extremely low decrease in the $m_{\mathrm{G}} X$ at initial was seen in run with $\Delta$ ddh mutant. The initial rates of endogenous glucose consumption of GT strain, $\Delta \mathrm{ddh}$ mutant and $\Delta \mathrm{adh} \Delta \mathrm{ddh}$ mutant were $0.00208,0.000417$ and $0.00125 \mu \mathrm{mol} \mathrm{mL} \mathrm{m}^{-1} \mathrm{~h}^{-1}$, respectively. The initial hydrogen production of mutants is unrelated to endogenous glucose consumption. The decrease in the $m_{\mathrm{G}} X$ with time is highest from 24 to $48 \mathrm{~h}$ in runs with GT strain and $\Delta \mathrm{ddh}$ mutant, and from 0 to $24 \mathrm{~h}$ in run with $\Delta \mathrm{adh} \Delta \mathrm{ddh}$ mutant. The yields of hydrogen on endogenous glucose $\left(Y_{\mathrm{H} 2 / \mathrm{G}}\right)$ in GT strain and in $\Delta \mathrm{ddh}$ mutant evaluated in this period are 6.67 and 10.0 , respectively. The $Y_{\mathrm{H} 2 / \mathrm{G}}$ in $\Delta \mathrm{adh} \Delta \mathrm{ddh}$ mutant is constant at 26 from $0 \mathrm{~h}$ to $72 \mathrm{~h}$.

No decrease in $m_{\mathrm{G}} X$ is seen from 48 to $96 \mathrm{~h}$ in run with GT strain, from 0 to $24 \mathrm{~h}$ and 48 to $72 \mathrm{~h}$ in run with $\Delta$ ddh mutant and from 24 to $72 \mathrm{~h}$ in run with $\Delta \mathrm{adh} \Delta \mathrm{ddh}$ mutant. The molecules of NAD(P)H for NiFe-hydrogenase are found to be mainly supplied by oxidative reactions other than glycolysis such as turnover of proteins, membrane lipids and PHB.

The decrease in $m_{\mathrm{G}} X$ with time is highest from 24 to $48 \mathrm{~h}$ in runs with GT strain and $\Delta \mathrm{ddh}$ mutant, and from 0 to 24 $\mathrm{h}$ in run with $\Delta \mathrm{adh} \Delta \mathrm{ddh}$ mutant. The yields of hydrogen on endogenous glucose $\left(Y_{\mathrm{H} 2 / \mathrm{G}}\right)$ in GT strain and in $\Delta \mathrm{ddh}$ mutant evaluated in this period are 6.67 and 10.0, respectively. The $Y_{\mathrm{H} 2 / \mathrm{G}}$ in $\Delta \mathrm{adh} \Delta \mathrm{ddh}$ mutant is constant at 26 from $0 \mathrm{~h}$ to $72 \mathrm{~h}$.

The present results are obtained in runs with inocula from late-logarithmic growth phase. If logarithmically growing cells are inoculated into dark anaerobic nitrate-free HEPES buffer solution, the $m_{\mathrm{G}} X$ increases in the first $24 \mathrm{~h}$ and then decreases after $24 \mathrm{~h}$ (data not shown). The inoculum $m_{\mathrm{G}} X$ levels of GT strain, $\Delta \mathrm{ddh}$ mutant and $\Delta \mathrm{adh} \Delta \mathrm{ddh}$ mutant were $0.21,0.17$ and $0.14 \mu \mathrm{molmL}^{-1}$, respectively. Figure 4 (b) shows that the $m_{\mathrm{G}} X$ at $96 \mathrm{~h}$ of runs with GT strain, $\Delta \mathrm{ddh}$ mutant and $\Delta \mathrm{adh} \Delta \mathrm{ddh}$ mutant were $0.06,0.07$, and $0.07 \mu \mathrm{mol} \mathrm{mL}{ }^{-1}$, respectively. The $m_{\mathrm{G}} X$ of $\Delta \mathrm{adh} \Delta \mathrm{ddh}$ mutant is relatively stable with time.

Cell weight consumption characteristics in the absence of glucose: Concentration of dry cell weight of GT strain or $\Delta$ adh $\Delta$ ddh mutant slightly decreased with time, while that of $\Delta$ ddh mutant was almost not varied with time (Figure 4(c)).

Lactate production characteristics in the absence of glucose: The production of lactate in GT strain started right after dark incubation Although the deletion of ddh genes is confirmed in Figure 2, the time courses of lactate concentration of runs with $\Delta \mathrm{ddh}$ mutant and with $\Delta \mathrm{adh} \Delta \mathrm{ddh}$ mutant show the production of trace amount of lactate. Lactate concentrations of runs with $\Delta \mathrm{ddh}$ and $\Delta$ adhddh mutants at $96 \mathrm{~h}$ were extremely low as 0.03 and $0.01 \mu \mathrm{mol}$ $\mathrm{mL}^{-1}$, respectively. These trace amount represent the generation of $\Delta \mathrm{ddh}$ photype deficient cells from $\Delta \mathrm{ddh}$ mutant and $\Delta \mathrm{adh} \Delta \mathrm{ddh}$ mutant during photosynthesis on antibiotic-free BG-11 medium and dark incubation on antibiotic-free HEPES buffer solution.

The specific production rate of lactate by GT strain in the first $24 \mathrm{~h}$ was $0.000397 \mu \mathrm{mol} \mu \mathrm{mol} \mathrm{mg} \mathrm{m}^{-1} \mathrm{~h}^{-1}$. The increases in lactate concentration in the incubation of $\Delta \mathrm{ddh}$ mutant and $\Delta \mathrm{adh} \Delta \mathrm{ddh}$ on glucose in the first $24 \mathrm{~h}$ were $0.01 \mu \mathrm{mol} \mathrm{mL} L^{-1}$ and $0 \mu \mathrm{mol} \mathrm{mL}^{-1}$, respectively, hence the fraction of $\Delta \mathrm{ddh}$ photype deficient cells in $\Delta \mathrm{ddh}$ cells and $\Delta$ adh $\Delta$ ddh cells are analyzed to be 0.5 and 0 , respectively. Lactate concentrations at $96 \mathrm{~h}$ of runs with $\Delta \mathrm{ddh}$ and $\Delta$ adhddh mutants were extremely low as 0.03 and $0.01 \mu \mathrm{mol} \mathrm{mL}^{-1}$, respectively. The initial yield of lactate on endogenous glucose of GT strain was 0.4 , which shows that the relatively large portion of degradated-glycogen is utilized not for the synthesis of lactate. Although hydrogen production rate and endogenous glucose consumption rate decreased with time, lactate production rate was acceralated after $48 \mathrm{~h}$. The carbon for lactate production after $48 \mathrm{~h}$ appears to be supplied from not only endogenous glucose but also other carboneous compounds.

Acetate production characteristics in the absence of glucose: Acetate concentration is about one-tenth of lactate concentration (Figure 4(e)). Acetate is not detected in the incubation of $\Delta \mathrm{adh} \Delta \mathrm{ddh}$ mutant. The production of acetate delays for $24 \mathrm{~h}$ in the incubations of GT strain and $\Delta \mathrm{ddh}$ mutant. No difference is observed in the acetate production in GT strain and in $\Delta$ ddh mutant from $24 \mathrm{~h}$ to $72 \mathrm{~h}$. The acetate production rate in this period was $0.00417 \mu \mathrm{mol} \mathrm{mL} \mathrm{L}^{-1} \mathrm{~h}^{-1}$. After $72 \mathrm{~h}$, acetate production was activated in GT strain but turned to consumption in $\Delta$ ddh mutant. The acetate consumption after $72 \mathrm{~h}$ in $\Delta \mathrm{ddh}$ mutant appears to show an oxidation of acetate to carbon dioxide in incomplete TCA cycle. In $\Delta \mathrm{ddh}$ mutant, acetate appears to be redirected to compensate the damaged cell constituting materials for survival. Acetate consumption in $\Delta \mathrm{ddh}$ mutant after $72 \mathrm{~h}$ is not seen in GT strain that represents high activity in endogenous glucose consumption. In GT strain, degradation of endogenous glucose likely contributes to be directed to biochemical synthesis for survival. Different from mutant, GT strain processed actively in glycolysis by converting glycogen lactate and acetate.

Ethanol production characteristics in the absence of glucose: Ethanol concentration at $96 \mathrm{~h}$ of runs with GT strain, $\Delta$ ddh mutant and $\Delta$ adh $\Delta$ ddh mutant was extremely low as $0.7,1.0$ and $0.4 \mu \mathrm{mol} \mathrm{mL}^{-1}$, respectively. These results show that the specific rates of ethanol production by GT strain and $\Delta \mathrm{ddh}$ mutant were 0.00283 and $0.00404 \mu \mathrm{mol}$ 
$\mathrm{mg}^{-1} \mathrm{~h}^{-1}$, respectively. The ethanol production of $\Delta \mathrm{ddh}$ mutant was higher than that of GT strain. The excess NADH molecules that were generated by elimination of lactate hydrogenase activity appears to be redirected to alcohol dehydrogenase. Drop of ethanol concentration of run with $\Delta \mathrm{adh} \Delta$ ddh mutant from that with $\Delta$ ddh mutant partially verifies the successful deletion of the genes coding for adh. Incomplete elimination of ethanol production in run with $\Delta \mathrm{adh} \Delta \mathrm{ddh}$ mutant shows the generation of $\Delta \mathrm{adh}$ photype deficient cells from $\Delta \mathrm{adh} \Delta \mathrm{ddh}$ mutant
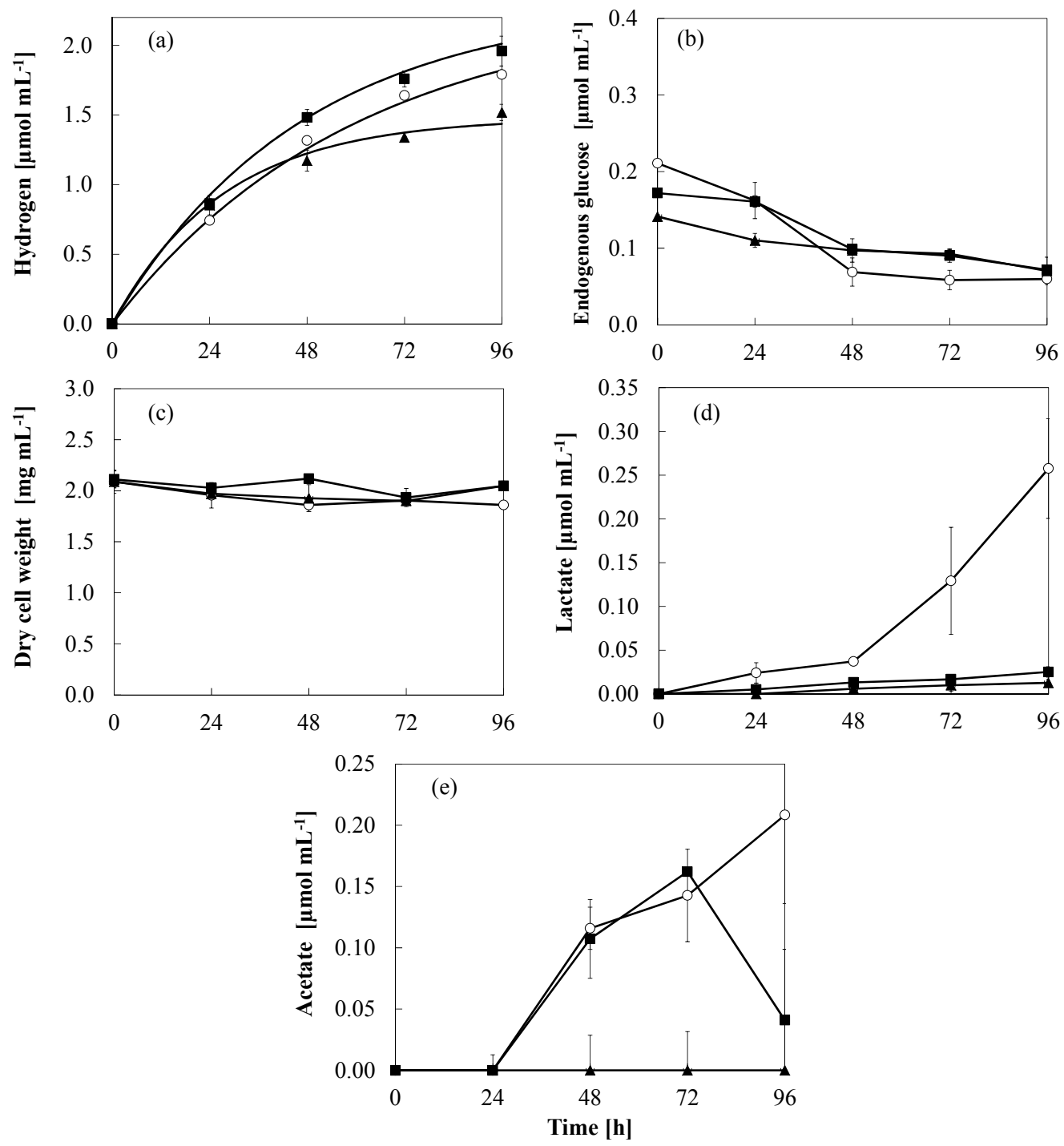

Figure 4. Time courses of culture variables for dark anaerobic hydrogen production of cells of GT strain (०), $\Delta$ ddh mutant $(\boldsymbol{\square})$ and $\triangle \mathrm{adh} \Delta \mathrm{ddh}$ mutant $(\boldsymbol{\Delta})$ in HEPES buffer solutions. Quantities measured include the moles per culture volume of (a) hydrogen and (b) the moles of endogenous glucose in glycogen, and the concentrations of (c) dry cell weight, (d) lactate and (e) acetate. Experiments were carried out in duplicate

\subsection{Characteristics of Dark Anaerobic Nitrate-Free Hydrogen Production in the Presence of Glucose}

In the second series, photoautotrophic cells of GT strain, $\Delta$ ddh mutant and $\Delta \mathrm{adh} \Delta \mathrm{ddh}$ in late-logarithmic growth phase were harvested and incubated with $X$ at $2.58 \mathrm{mg} \mathrm{mL}^{-1}$ in dark anaerobic nitrate-free antibiotic-free HEPES buffer solution with $5 \mathrm{mmol} \mathrm{mL}^{-1}$ exogenous glucose. Figure 5 shows the time courses of (a) the number of moles of hydrogen per culture volume $\left(y_{\mathrm{H} 2}\right)$, (b) exogenous glucose concentration $\left(c_{\mathrm{S}}\right)$, (c) the number of moles of endogenous glucose per culture volume $\left(m_{\mathrm{G}} X\right),(\mathrm{d})$ dry cell weight concentration $(X)$, (e) lactate concentration $\left(c_{\mathrm{L}}\right)$, (f) acetate concentration $\left(c_{\mathrm{A}}\right)$ and $(\mathrm{g})$ ethanol concentration $\left(c_{\mathrm{E}}\right)$. Different from curves in Figure 4, curves in Figure 5 represent the heterotrophic growth of GT strain, $\Delta$ ddh mutant and $\Delta$ adh $\Delta$ ddh mutant on exogenous glucose. Production of lactate, acetate and ethanol in GT strain were also become eminent. 

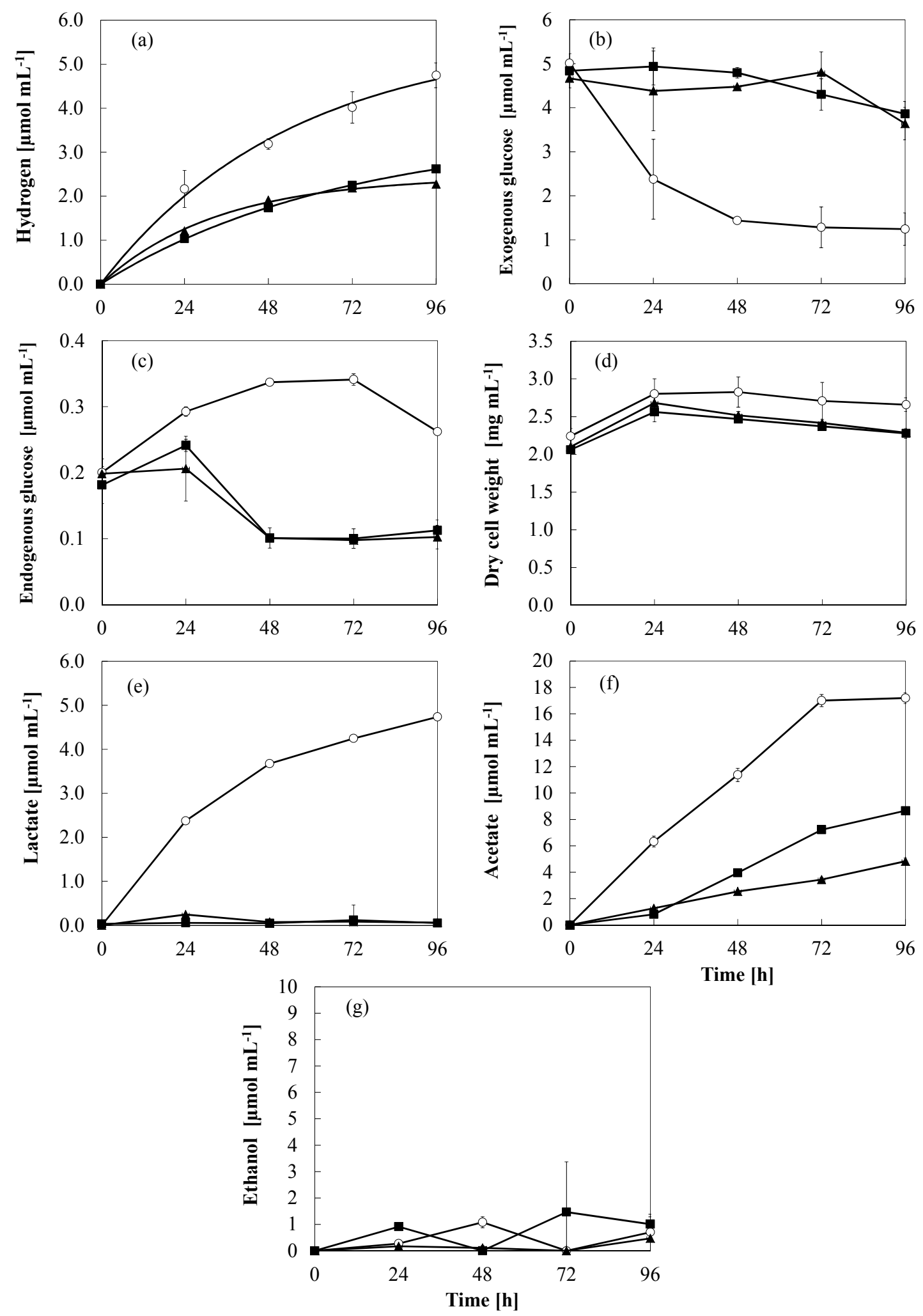

Figure 5. Time courses of culture variables for dark anaerobic hydrogen production of cells of GT strain (०), $\Delta \mathrm{ddh}$ mutant $(\boldsymbol{\square})$ and $\Delta \mathrm{adh} \Delta \mathrm{ddh}$ mutant $(\boldsymbol{\Delta})$ in HEPES buffer solutions supplemented with $5 \mu \mathrm{mol}^{\mathrm{mL}} \mathrm{mL}^{-1}$ glucose. Quantities measured include (a) the moles of hydrogen per culture volume, (b) the concentration of exogenous glucose, (c) the moles of endogenous glucose in glycogen per culture volume, (d) the concentration of cell mass, (e) the concentration of lactate, (f) the concentration of acetate and (g) the concentration of ethanol. Experiments were carried out in duplicate 
Hydrogen production characteristics in the presence of glucose: Figure 5(a) shows that the $y_{\mathrm{H} 2}$ versus time data of runs with exogenous glucose are fitted by Eq.(1). The parameters $r_{\mathrm{H} 2,0}, k$ and $y_{\mathrm{H} 2, \mathrm{f}}$ for curve-fittings are tabulated in Table1. The calculated $y_{\mathrm{H} 2}$ agrees relatively well with the observed $y_{\mathrm{H} 2}$. The $y_{\mathrm{H} 2, \mathrm{f}}$ of glucose-supplemented runs with GT strain, $\Delta$ ddh mutant and $\Delta \mathrm{adh} \Delta \mathrm{ddh}$ mutant were $5.61,3.48$ and $2.45 \mu \mathrm{mol} \mathrm{mL}^{-1}$, respectively, which were $2.46,1.50$ and 1.65 -fold, respectively over runs without glucose. It becomes eminent that exogenous glucose elevates dark anaerobic hydrogen production in GT strain, $\Delta$ ddh mutant and $\Delta \mathrm{adh} \Delta \mathrm{ddh}$ mutant. The $r_{\mathrm{H} 2,0}$ of Table 1 is highest for run with GT strain, lowest for run with $\Delta \mathrm{ddh}$ mutant and second lowest for run with $\Delta \mathrm{adh} \Delta \mathrm{ddh}$ mutant. This order is quite different from that of runs without glucose. Intracellular electrons increased at the dark anaerobic inoculation is likely directed to NiFe-hydrogenase in the absence of glucose, however, they are directed not only NiFe-hydrogenase but also many metabolic pathways including cell growth, acid fermentation that are triggered in the presence of glucose. Hence $r_{\mathrm{H} 2,0}$ of $\Delta$ ddh mutant under exogenous glucose solution couldn't show highest activity. Highest $y_{\mathrm{H} 2, \mathrm{f}}$ is found to be achieved utilizing GT strain in the presence of exogenous glucose. The attainable level of $y_{\mathrm{H} 2}$ by $\Delta \mathrm{ddh}$ mutant and $\Delta \mathrm{adh} \Delta \mathrm{ddh}$ is less than that of GT strain. When glucose was present, the highest $y_{\mathrm{H} 2,1}$ was GT strain, second highest is $\Delta \mathrm{ddh}$ strain and the lowest is $\Delta \mathrm{adh} \Delta \mathrm{ddh}$ mutant. The elimination of adh activity resulted to decrease $y_{\mathrm{H} 2,1}$ that was 0.49 times that of GT strain in runs with exogenous glucose.

Exogenous glucose consumption characteristics in the presence of glucose: Curves in Figure 5(b) show that consumption activity of exogenous glucose by GT strain is higher than that by $\Delta$ ddh mutant and $\Delta \mathrm{adh} \Delta \mathrm{ddh}$ mutant. Glucose consumption of GT strain was active in the first $48 \mathrm{~h}$, while that of $\Delta \mathrm{ddh}$ mutant and that of $\Delta \mathrm{adh} \Delta \mathrm{ddh}$ mutant were inactive in the first $72 \mathrm{~h}$. Conversions of glucose at $96 \mathrm{~h}$ by GT strain, $\Delta \mathrm{ddh}$ mutant and $\Delta \mathrm{adh} \Delta \mathrm{ddh}$ mutant were $0.76,0.19$ and 0.23 , respectively. The observed block of exogenous glucose assimilation by the disruption of ddh genes was not anticipated.

Endogenous glucose production/consumption characteristics in the presence of glucose: The time courses of the $m_{\mathrm{G}} X$ show that, during $96 \mathrm{~h}$ incubation, the $m_{\mathrm{G}} X$ of mutant increased during $24 \mathrm{~h}$ and become constant after $48 \mathrm{~h}$ whereas the $m_{\mathrm{G}} X$ of GT show accumulation of endogenous glucose from the beginning to $72 \mathrm{~h}$ (Figure 5(b)). Although hydrogen production in GT strain was highest at initial, an increase in the $m_{\mathrm{G}} X$ at initial was seen in run with GT strain. The initial rate of endogenous glucose accumulation of GT, $\Delta$ ddh mutant and $\Delta \mathrm{adh} \Delta \mathrm{ddh}$ mutant were $0.00384,0.00250$ and $0.00032 \mu \mathrm{mol} \mathrm{mL}{ }^{-1} \mathrm{~h}^{-1}$, respectively. The decrease in $m_{\mathrm{G}} X$ with time is not observed from 48 to $96 \mathrm{~h}$ in runs with $\Delta \mathrm{ddh}$ mutant and $\Delta \mathrm{adh} \Delta \mathrm{ddh}$ mutant, they were constant. The endogenous glucose of GT strain was increasing during fermentation with a sharp drop after $72 \mathrm{~h}$. The present results are obtained in runs with inocula from late-logarithmic growth phase.

Cell weight production/degradation characteristics in the presence of glucose: Dry cell weight concentration of GT strain increased in the first $24 \mathrm{~h}$, kept constant between 24 and $48 \mathrm{~h}$, and decreased quite slightly after $48 \mathrm{~h}$. The initial increase in dry cell weight concentration is associated with the reduction in exogenous glucose concentration. This association confirms the heterotrophic growth of GT strain on glucose. The rate of decrease in dry cell weight concentration after $48 \mathrm{~h}$ is comparable with the initial decrease in dry cell weight concentration of run without glucose. The time course of dry cell weight concentration of $\Delta \mathrm{adh} \Delta \mathrm{ddh}$ mutant is comparable with that of $\Delta \mathrm{ddh}$ mutant. Dry cell weight concentrations of $\Delta \mathrm{ddh}$ mutant and $\Delta \mathrm{adh} \Delta \mathrm{ddh}$ mutant increased in the first $24 \mathrm{~h}$, and decreased after $24 \mathrm{~h}$.

Interestingly, when cells of $\Delta \mathrm{ddh}$ mutant and $\Delta \mathrm{adh} \Delta \mathrm{ddh}$ mutant grew in the first $24 \mathrm{~h}$, concentrations of exogenous glucose were not varied. No decrease in the number of moles of endogenous glucose per culture volume in the first $24 \mathrm{~h}$ of runs with $\Delta \mathrm{ddh}$ mutant and $\Delta \mathrm{adh} \Delta \mathrm{ddh}$ mutant is seen in Figure 5(c). Growth of $\Delta \mathrm{ddh}$ mutant and $\Delta \mathrm{adh} \Delta \mathrm{ddh}$ mutant appears to be triggered by exogenous glucose. Combination of the time courses of exogenous glucose, endogenous glucose and dry cell weight suggests that carbon source for cell growth of $\Delta$ ddh mutant is not exogenous glucose or endogenous glucose but unidentified intracellular organic compounds.

Lactate production characteristics in the presence of glucose: Lactate concentration at $96 \mathrm{~h}$ of run with GT strain in the presence of glucose was $4.74 \mu \mathrm{mol} \mathrm{mL}^{-1}$ which is 18 times more than that in the absence of glucose. This result shows that exogenous glucose is converted to lactate by GT strain. The yield of lactate on dry cell weight in the first $24 \mathrm{~h}$ is $3.95 \mu \mathrm{mol} \mathrm{mg}^{-1}$. The increases in lactate concentration in the incubation of $\Delta \mathrm{ddh}$ mutant and $\Delta \mathrm{adh} \Delta \mathrm{ddh}$ mutant on glucose in the first $24 \mathrm{~h}$ were $0.03 \mu \mathrm{mol} \mathrm{mL}^{-1}$, and $0.07 \mu \mathrm{mol} \mathrm{mL}^{-1}$, respectively, hence the fraction of $\Delta$ ddh photype deficient cells in $\Delta$ ddh mutant and $\Delta \mathrm{adh} \Delta \mathrm{ddh}$ mutant are analyzed to be 0.00362 and 0.00844 , respectively. Lactate concentrations at $96 \mathrm{~h}$ of runs with with $\Delta \mathrm{ddh}$ and $\Delta$ adhddh mutants were extremely low as 0.05 and $0.06 \mu \mathrm{mol} \mathrm{mL}{ }^{-1}$, respectively. The deletion of ddh genes in this work possibly altered the intracellular balance between $\mathrm{NAD}(\mathrm{P}) \mathrm{H}$ and $\mathrm{NAD}(\mathrm{P})^{+}$towards shifting-up $\mathrm{NAD}(\mathrm{P}) \mathrm{H}$ level. This $\mathrm{NAD}(\mathrm{P}) \mathrm{H}$ shifting-up is important because NADH and NADPH are essential reductive compounds for hydrogen production on NiFe-hydrogenase. The increase in the level of $\mathrm{NAD}(\mathrm{P}) \mathrm{H}$ results in the increase in the level of ATP and 
subsequently inactivates phosphofructokinase. Assimilation of exogenous glucose by $\Delta$ ddh mutant appears to be blocked by the inactivation of phosphofructokinase, brought by the elimination of the genes coding for ddh.

Acetate production characteristics in the presence of glucose: Acetate production is highly activated by exogenous glucose in GT strain. Exogenous glucose stimulated acetate production also in $\Delta$ ddh mutant and $\Delta \mathrm{adh} \Delta \mathrm{ddh}$ mutant. After $96 \mathrm{~h}$, acetate concentrations of runs with GT strain, $\Delta$ ddh mutant and $\Delta$ adhddh mutant in the presence of exogenous glucose were $17.19,8.66$ and $4.83 \mu \mathrm{mol} \mathrm{mL}^{-1}$, respectively, that were about more than 100 times those in the absence of exogenous glucose. Acetate is one of the terminal carbon release compound from glucose consumption. Glucose consumption and acetate production of GT strain were higher than those of $\Delta \mathrm{ddh}$ and $\Delta \mathrm{adh} \Delta \mathrm{ddh}$ mutants.

Ethanol production characteristics in the presence of glucose: Ethanol concentration at $96 \mathrm{~h}$ of runs with GT strain, $\Delta \mathrm{ddh}$ mutant and $\Delta \mathrm{adh} \Delta \mathrm{ddh}$ mutant was extremely low as $0.70,1.01$ and $0.47 \mu \mathrm{molmL}^{-1}$, respectively. Extremely low production of ethanol by the incubation of $\Delta \mathrm{adh} \Delta \mathrm{ddh}$ mutant from antibiotic-free photoautotrophic culture verifies the successful deletion of the genes coding for $a d h$. The yield of ethanol on dry cell weight of GT strain in the first $24 \mathrm{~h}$ is $0.45 \mu \mathrm{mol} \mathrm{mg}{ }^{-1}$. The increase in ethanol concentration in the incubation of $\Delta \mathrm{adh} \Delta \mathrm{ddh}$ mutant on glucose in the first $24 \mathrm{~h}$ was $0.17 \mu \mathrm{mol} \mathrm{mL}^{-1}$, hence the fraction of $\Delta \mathrm{adh}$ photype deficient cells in $\Delta \mathrm{adh} \Delta \mathrm{ddh}$ cells are analyzed to be 0.180 .

If stability of hydrogen production is evaluated in low value of the parameter $k$ shown in Table 1 , incubation of $\Delta$ ddh mutant in the presence of exogenous glucose represents most stable hydrogen production condition. This stabilization is not harnessed in the attainable level of hydrogen $\left(y_{\mathrm{H} 2, \mathrm{f}}\right)$, which is highest in run with GT strain in the presence of exogenous glucose. When viewed over the parameters in this study, the increase in the initial hydrogen production rate $\left(r_{\mathrm{H} 2,0}\right)$ is found to be crucial to elevate the level of $y_{\mathrm{H} 2, \mathrm{f}}$. Elimination of ddh and adh genes is effective to increase the level of $r_{\mathrm{H} 2,0}$ in the absence of exogenous glucose, however, it becomes ineffective in the presence of exogenous glucose. Redox balance in the presence of exogenous glucose is found to be different from that in the absence of exogenous glucose.

\section{Discussion}

Our results show that exogenous glucose shifts up initial rate of hydrogen production in GT strain, $\Delta$ ddh mutant and $\Delta \mathrm{adh} \Delta \mathrm{ddh}$ mutant, and that, in the absence of exogenous glucose, initial hydrogen production rates of $\Delta \mathrm{ddh}$ mutant and $\Delta \mathrm{adh} \Delta \mathrm{ddh}$ mutant are higher than that of GT strain, but in the presence of glucose, that of $\Delta \mathrm{ddh}$ mutant and $\Delta \mathrm{adh} \Delta \mathrm{ddh}$ mutant are lower than that of GT strain. The highest attainable level of the number of moles of hydrogen per culture volume of $5.61 \mu \mathrm{mol} \mathrm{mL}^{-1}$ is achieved with GT strain in the presence of glucose due to heterotrophic growth of GT strain by assimilating exogenous glucose and producing endogenous glucose, lactate and acetate. The lowest attainable level of hydrogen at $2.28-2.45 \mu \mathrm{mol} \mathrm{mL} \mathrm{m}^{-1}$ is achieved with GT strain or $\Delta \mathrm{ddh}$ mutant in the absence of glucose and with $\Delta \mathrm{adh} \Delta \mathrm{ddh}$ mutant in the presence of glucose.

In cyanobacterial research, conversion of glucose 6-P to pyruvate is assumed to occur through OPP pathway. Complete decomposition of $1 \mu \mathrm{mol}$ endogenous glucose of reserved glycogen to $5 / 3 \mu$ mole pyruvate and $1 \mu$ mole carbon dioxide through OPP pathway produces $11 / 3 \mu$ mole $\mathrm{NAD}(\mathrm{P}) \mathrm{H}$. The stoichiometry of ddh and adh represent that conversion of $1 \mu$ mole pyruvate to $1 \mu$ mole lactate consumes $1 \mu$ mole NADH and that conversion of $1 \mu$ mole pyruvate to $1 \mu$ mole ethanol via acetaldehyde also consumes $1 \mu$ mole NADPH.

Conversion of $1 \mu$ mole pyruvate to $1 \mu$ mole acetyl-CoA and $1 \mu$ mole carbon dioxide on pyruvate oxidoreductase (nif J) generates $1 \mu$ mole reduced ferredoxin from oxidized ferredoxin. Conversion of acetyl-CoA to acetate via acetyl-P on phosphate acetyltransferase (pta) and acetate kinase (ack A) (Juntarajumnong et al., 2007) in the acetate-forming direction requires $1 \mu \mathrm{mol} \mathrm{ADP}$ and $1 \mu \mathrm{mol}$ Pi for oxidation. Complete oxidation of $1 \mu \mathrm{mol}$ pyruvate to $3 \mu \mathrm{mol}$ carbon dioxide through incomplete TCA cycle via acetyl-CoA produces $36 / 5 \mu \mathrm{mol}$ NADPH.

Deletion of NAD(P)H-consuming dehydrogenase pathways redirects more NAD(P)H to NiFe-hydrogenase and affects to increase hydrogen production rate. Successful mutant constructions are confirmed by a drastical drop in lactate production and ethanol production by corresponding mutants. Although extremely low amounts of lactate and ethanol were detected in run with $\Delta \mathrm{ddh}$ mutant and $\Delta \mathrm{adh} \Delta \mathrm{ddh}$ mutant, these are regarded as the appearance of wild type strain since antibiotics were not utilized for main culture and dark anaerobic incubation of those mutants. Production rates of lactate and ethanol by mutants in Figures 4 and 5 are $0 \mu \mathrm{mol} \mathrm{mL} \mathrm{L}^{-1} \mathrm{~h}^{-1}$, even though trace amounts of lactate and ethanol were detected for antibiotic-free conditions. During the first $24 \mathrm{~h}$, acetate productions in GT strain, $\Delta$ ddh mutant and $\Delta \mathrm{adh} \Delta \mathrm{ddh}$ mutant are negligible small. Global metabolism of this strain accumulates $\mathrm{NAD}(\mathrm{P}) \mathrm{H}$ that is generated by glycolysis through OPP pathway, oxidation of pyruvate through incomplete TCA cycle and turnover of proteins, membrane lipids and PHB, and consumes it on NiFe-hydrogenase, 
ddh, adh and other oxidative reactions to keep redox homeostasis. At the beginning of dark incubation, the inoculum cells of $\Delta \mathrm{ddh}$ mutant and $\Delta \mathrm{adh} \Delta \mathrm{ddh}$ mutant from photosynthesis contain high amount of NAD $(\mathrm{P}) \mathrm{H}$. The incubation of cells in nitrate-free solution in the dark triggers turnover of glycogen, proteins, membrane lipids and PHB. Turnover reactions are accompanied by accumulation of $\mathrm{NAD}(\mathrm{P}) \mathrm{H}$. The excess NAD $(\mathrm{P}) \mathrm{H}$ is utilized for hydrogen production, lactate production and ethanol production via acetate production. In GT strain, the summation of initial consumption rates of $\mathrm{NAD}(\mathrm{P}) \mathrm{H}$ by NiFe-hydrogenase and lactate dehydrogenase is 0.0317 $\mu \mathrm{mol} \mathrm{mL} \mathrm{L}^{-1} \mathrm{~h}^{-1}$ that is higher than the theoretical initial production rate of $\mathrm{NAD}(\mathrm{P}) \mathrm{H}$ at $0.0250 \mu \mathrm{mol} \mathrm{mL}^{-1} \mathrm{~h}^{-1}$ from OPP pathway and incomplete TCA cycle, hence assumption is raised that, $\mathrm{NAD}(\mathrm{P}) \mathrm{H}$ for NiFe-hydrogenase is found to be supplied not only by glycolysis but also by turnover of proteins, membrane lipids and PHB.

In $\Delta$ ddh mutant under exogenous glucose-free condition, even though the activity of ddh is absent, the theoretical initial production rate of $\mathrm{NAD}(\mathrm{P}) \mathrm{H}$ from OPP pathway and incomplete TCA cycle at $0.0050 \mu \mathrm{mol} \mathrm{mL}^{-1} \mathrm{~h}^{-1}$ is only $14 \%$ of $\mathrm{NAD}(\mathrm{P}) \mathrm{H}$ consumed by NiFe-hydrogenase. At the beginning of dark incubation, the major $\mathrm{NAD}(\mathrm{P}) \mathrm{H}$ generating reaction for hydrogen production in $\Delta \mathrm{ddh}$ mutant is found to be turnover reactions other than glycolysis Under exogenous glucose condition, in the first $24 \mathrm{~h}$, the carbon flux at glucose 6-P is directed to glycogen synthesis, cell growth, lactate production, acetate production and ethanol.

In $\Delta \mathrm{adh} \Delta \mathrm{ddh}$ mutant under exogenous glucose-free condition, summation of theoretical production rates of $\mathrm{NAD}(\mathrm{P}) \mathrm{H}$ by OPP pathway and incomplete TCA cycle is $0.0150 \mu \mathrm{mol} \mathrm{mL}^{-1} \mathrm{~h}^{-1}$ that is $42 \%$ of NAD(P)H consumed by NiFe-hydrogenase. About a half of $\mathrm{NAD}(\mathrm{P}) \mathrm{H}$ is found to be supplied by turnover of proteins, membrane lipids and PHB.

Although hydrogen production rate is improved, other competitive pathway such as nitrate reductase may play a major role in electron sink. A previous work reported a significant improvement in hydrogen production up to more than 20-folds on nitrate-deprived BG-11 medium (Baebprasert et al. 2011).

Our experimental results present a knowledge that the deletion of ddh genes and/or adh genes is useful to increase reductive potential of Synechocystis sp. strain PCC6803-GT against cellular property of redox homeostasis. Exposure of cells to dark anaerobic nitrate-free environment triggers the adaptation of cells to new redox homeostasis state, hence above reductive potential is unstable with time.

The $\Delta \mathrm{adh} \Delta \mathrm{ddh}$ mutant constructed in this study is characterized by a $37 \%$ decrease in the initial amount of endogenous glucose per culture volume, a $15 \%$ increase in the initial hydrogen production rate, $45 \%$ decrease in the attainable level of hydrogen, stable level in dry cell weight concentration, stable level in endogenous glucose, almost no production of lactate and no production of acetate. An addition of reducing sugar to HEPES buffer solution containing $\Delta \mathrm{adh} \Delta \mathrm{ddh}$ mutant appears to elevate the amount of endogenous glucose per culture volume, which is promising to elevate hydrogen production.

\section{Conclusions}

This study provides additional information as to the elevation of dark anaerobic hydrogen production in a glucose tolerant mutant of Synechocystis sp. strain PCC6803 by deleting the genes coding for lactate dehydrogenase and alcohol dehydrogenase that compete $\mathrm{NAD}(\mathrm{P}) \mathrm{H}$ with hydrogen production of NiFe-hydrogenase. Although mutation cannot affect the attainable level in number of moles of hydrogen per culture volume, it results a $15 \%$ increase in the initial hydrogen production rate. This finding have led to a mechanism that the initial turnover of proteins, membrane lipids and PHB is related to the mutation. Glycogen turnover was reduced in mutants. Glucose is a good substrate for hydrogen production improvement. However, lower affinity of glucose consumption by mutant cells inhibits mutants to turn glucose for glycogen accumulation. Although the homeostasis of Synechocystis sp. strain PCC6803 in terms of alternations of its metabolic functions limit metabolic engineering approaches to increase hydrogen production, mutants certainly have a great potential for responding to the shift in environments. More data will be needed before the combined effects of mutation and some environmental supplement become apparent.

\section{References}

Antal, T. K., \& Lindblad, P. (2005). Production of $\mathrm{H}_{2}$ by sulphur-deprived cells of the unicellular cyanobacteria Gloeocapsa alpicola and Synechocystis sp. PCC 6803 during dark incubation with methane or at various extracellular pH. J Appl Microbiol, 98(1), 114-120. http://dx.doi.org/10.1111/j.1365-2672.2004.02431.x

Baebprasert, W., Jantaro, S., Khetkorn, W., Lindblad, P., \& Incharoensakdi, A. (2011). Increased $\mathrm{H}_{2}$ production in the cyanobacterium Synechocystis sp. strain PCC 6803 by redirecting the electron supply via genetic engineering of the nitrate assimilation pathway. Metab Eng, 13(5), 610-616. http://dx.doi.org/10.1016/j. ymben.2011.07.004 
Cournac, L., Guedeney, G., Peltier, G., \& Vignais, P. M. (2004). Sustained photoevolution of molecular hydrogen in a mutant of Synechocystis sp. strain PCC 6803 deficient in the type I NADPH-dehydrogenase complex. $J$ Bacteriol, 186(6), 1737-1746.

Dehring, U., Kramer, D., \& Ziegler, K. (2012). Selection of ADH in genetically modified cyanobacteria for the production of ethanol. U.S. Patent No. 8,163,516. Washington, DC: U.S. Patent and Trademark Office.

Gao, Z., Zhao, H., Li, Z., Tan, X., \& Lu, X. (2012). Photosynthetic production of ethanol from carbon dioxide in genetically engineered cyanobacteria. Energy Environ Sci, 5(12), 9857-9865. http://dx.doi.org/10.1039/c2ee $22675 \mathrm{~h}$

Juntarajumnong, W., Eaton-Rye, J. J., \& Incharoensakdi, A. (2007). Two-component signal transduction in Synechocystis sp. PCC6803 under phosphate limitation: Role of acetyl phosphate. J Biochem and Mol Biol., 40(5), 708-714

Kufryk, G. I., Sachet, M., Schmetterer, G., \& Vermaas, W. F. J. (2002). Transformation of the cyanobacterium Synechocystis sp. PCC 6803 as a tool for genetic mapping: optimization of efficiency. FEMS Microbiology Letters, 206(2), 215-219. http://dx.doi.org/10.1111/j.1574-6968.2002.tb11012.x

Li, S., Lai, C., Cai, Y., Yang, X., Yang, S., Zhu, M., ... Wang, X. (2010). High efficiency hydrogen production from glucose/xylose by the ddh-deleted Thermoanaerobacterium strain. Bioresource Technology, 101(22), 8718-8724. http://dx.doi.org/10.1016/j.biortech.2010.06.111

Maeda, T., Sanchez-Torres, V., \& Wood, T. (2007). Enhanced hydrogen production from glucose by metabolically engineered Escherichia coli. Appl Microbiol Biotechnol, 77(4), 879-890. http://dx.doi.org/10.1007/s00253-007-1217-0

McNeely, K., Xu, Y., Bennette, N., Bryant, D. A., \& Dismukes, C. G. (2010). Redirecting Reductant Flux into Hydrogen Production via Metabolic Engineering of Fermentative Carbon Metabolism in a Cyanobacterium. Appl Environ Microbiol, 76, 5032-5038. http://dx.doi.org/10.1128/aem.00862-10

Prentki, P., \& Krisch, H. M. (1984). In vitro insertional mutagenesis with a selectable DNA fragment. Gene, 29(3), 303-313. http://dx.doi.org/10.1016/0378-1119(84), 90059-3

Rippka, R., Deruelles, J., Waterbury, J. B., Herdman, M., \& Stanier, R. Y. (1979). Generic assignments, strain histories and properties of pure cultures of cyanobacteria. Journal of General microbiology, 111(1), 1-61. http://dx.doi.org/10.1099/00221287-111-1-1

Shimakawa, G., Suzuki, M., Yamamoto, E., Nishi, A., Saito, R., Sakamoto, K., ... Miyake, C. (2013). Scavenging Systems for Reactive Carbonyls in the Cyanobacterium Synechocystis sp. PCC 6803. Biosci Biotechnol Biochem, 77(12), 2441-8. http://dx.doi.org/10.1271/bbb.130554

Yamamoto, T., Chongsuksantikul, A., Asami, K., \& Ohtaguchi, K. (2012). Improvement of anaerobic production of hydrogen in the dark by genetic mutation strains of Synechocystis sp. strain PCC 6803. J Biochem Technology, 4(2), 600-603

Yu, L., You, L., Liu, D., Hollinshead, W., Tang, Y. J., \& Zhang F. (2013). Development of Synechoystis sp PCC6803 as a phototrophic cell factory. Mar Drugs, 11, 2894-2916.

\section{Copyrights}

Copyright for this article is retained by the author(s), with first publication rights granted to the journal.

This is an open-access article distributed under the terms and conditions of the Creative Commons Attribution license (http://creativecommons.org/licenses/by/3.0/). 